\title{
Renography within 1 Hour of Renal Transplantation: Technical Feasibility and Clinical Utility
}

\author{
Abdel Moneim Omar ${ }^{a}$ Tahani Al-Saeed ${ }^{a}$ Alaa-Eldin Gawish ${ }^{b}$ \\ Sameera Tailji ${ }^{\mathrm{a}}$ Ali Khalaf Ibrahim ${ }^{\mathrm{a}}$ B. David Collier ${ }^{\mathrm{C}}$ \\ Abdelhamid H. Elgazzar ${ }^{\mathrm{C}}$ \\ Departments of a Nuclear Medicine and ${ }^{\mathrm{b}}$ Surgery, Organ Transplantation Center, Ministry of Health and \\ ${ }^{\mathrm{c}}$ Department of Nuclear Medicine, Faculty of Medicine, Kuwait University, Kuwait
}

\section{Key Words}

Renal transplant $\cdot$ Renography $\cdot$ Nuclear medicine $\cdot$

Acute tubular necrosis

\begin{abstract}
Objective: Renographies obtained within $1 \mathrm{~h}$ of renal transplantation were studied prospectively to evaluate their technical feasibility and potential clinical impact on successful treatment of immediate posttransplantation complications such as arterial or venous thrombosis, which require prompt diagnosis and management. Subjects and Methods: During December 1996 to December 1998, 127 renal transplants were performed. Ninety-four patients had complete renographic studies within $1 \mathrm{~h}$ of surgery. It was not possible to perform renography on 26 patients who were not sent to the Department of $\mathrm{Nu}$ clear Medicine within $1 \mathrm{~h}$ of transplant and 7 other patients who could not undergo a complete renogram because of their postoperative condition. Results: There was no complication attributed to transporting patients to the Department of Nuclear Medicine for these studies so soon after surgery. Of the 94 renographies obtained immediately following transplant surgery 46 were abnormal. However, when compared with the usual policy of obtaining baseline renograms between 12 and $72 \mathrm{~h}$ after surgery, treatment was changed for only 2 patients.
\end{abstract}

Radionuclide renography within $1 \mathrm{~h}$ of transplant surgery was technically feasible. Conclusion: Based on the results of this study the clinical utility of obtaining renography within $1 \mathrm{~h}$ posttransplant was minimal and hence we recommended that it should not be performed routinely but could be used on an individual basis when imminent intervention is highly likely.

Copyright $(2005$ S. Karger AG, Basel

\section{Introduction}

While radionuclide renography after renal transplantation has been advocated for many years, the examination is rarely performed shortly after the surgery. Many investigators have recommended obtaining a postoperative renogram - usually between 12 and $72 \mathrm{~h}$ following transplantation - as a baseline study [1-7]. This so-called baseline renography may identify acute tubular necrosis (ATN), most frequently seen in cadaveric allografts, and more importantly may be used for comparison with future renography performed to diagnose transplant rejection or other complications which may develop days, months, or years later. However, a study obtained between 12 and $72 \mathrm{~h}$ following transplantation could be thought of as late for the transplant surgeon wishing to identify vascular complications that

\section{KARGER \\ Fax +4161306 1234 E-Mail karger@karger.ch} www.karger.com
C 2005 S. Karger AG, Basel 1011-7571/05/0142-0111\$22.00/0

Accessible online at:

www.karger.com/mpp
Abdelhamid H. Elgazzar, MD

Department of Nuclear Medicine

Faculty of Medicine, PO Box 24923

13110 Safat (Kuwait)

Tel. +965 531 9592, Fax +965 533 8936, E-Mail aelgazzar49@hotmail.com 
may lead to graft necrosis if left untreated for even a short time.

Either arterial or venous thrombosis may occur during or shortly after renal transplantation [8-10]. Although such vascular complications rarely happen, prompt surgical intervention often will preserve the renal transplant. Therefore, surgeons at our institution suggested immediate postoperative confirmation of renal transplant arterial perfusion and renal vein patency. While duplex and color Doppler mode ultrasound have been used to confirm vascular patency $[8,9,11]$, surgeons at our institution prefer a radionuclide renogram which will both exclude vascular complications and also serve as a baseline study for comparison with future studies.

While many investigators have reported performing renography as early as $12 \mathrm{~h}$ following surgery, the clinical results of a performing of renography within $1 \mathrm{~h}$ of renal transplantation have not previously been described. Therefore, the aim of this study was to investigate the feasibility and potential clinical utility of such renography.

\section{Subjects and Methods}

During the period of December 1996 to December 1988, 127 postoperative renal transplant recipients (70 male and 57 female ranging in age from 13 to 69 years with a mean age of 41 years) underwent renography. Twenty-six patients were not brought to nuclear medicine within $1 \mathrm{~h}$. Thus, of the 127 transplant recipients, only 101 arrived in the Department of Nuclear Medicine within $1 \mathrm{~h}$ of surgery. These included 72 living related donors and 29 cadaveric transplant recipients.

All the renal transplant recipients were brought directly from surgery to the department where ongoing postoperative analgesia and respiratory care were adequately maintained. In addition, transplant surgeons were available to treat any vascular complications if indicated by the renography. Thus, a commitment of resources and degree of support not typically required for renography was maintained, which included the presence of the surgeon, anesthesiologist, surgical nurse, nuclear medicine physician, and nuclear medicine technologist in the Department of Nuclear Medicine for these special renographies.

For all studies, between 185 and $370 \mathrm{MBq}{ }^{99 \mathrm{~m}} \mathrm{Tc}$ MAG-3 were injected intravenously followed by a flow study ( 2 s per frame for $60 \mathrm{~s}$ ) and sequential imaging ( $30 \mathrm{~s} \mathrm{per} \mathrm{frame} \mathrm{for} \mathrm{additional} 29 \mathrm{~min}$ ). A large field-of-view gamma camera interfaced to a computer system allowed for digital image processing and quantitative analysis. Processing was performed by drawing a region of interest around the transplanted kidney, the ipsilateral internal iliac artery, and a background region. Time-activity curves for these regions were analyzed for the following parameters: perfusion index, time to maximum transplant uptake $\left(\mathrm{T}_{\max }\right)$, time to half-maximum transplant uptake $\left(\mathrm{T}_{1 / 2} \max \right)$, and functional uptake index. Both images and quantitative data were interpreted using previously described tech- niques and standards [7, 12-19]. Interpretation included visual analysis of the flow study and sequential functional images as well as quantitative analysis of $\mathrm{T}_{\max }, \mathrm{T}_{1 / 2 \max }$, perfusion index and functional uptake index (fig. 1).

\section{Results}

Of the 101 studies, 94 were of acceptable technical quality. For 7 patients, technical difficulties caused by the patient's postoperative condition [irritability and movement (5 patients) and blocked bladder catheter ( 2 patients)] made it impossible to complete the renographic examination. For these 7 patients, partial studies of generally limited diagnostic value were obtained. However, for all 7 of these patients the limited studies were adequate to exclude vascular complications requiring immediate surgical intervention. Thus, vascular complications were excluded for all the 101 patients. Accordingly, the protocol compliance rate during the immediate postoperative period was 101/127 (80\%) transplant recipients. The technical success rate for obtaining a full renogram within $1 \mathrm{~h}$ of surgery was $93 \%$ (94/101 patients). However, the success rate for ruling out vascular complications (when requested to do so by the transplant surgeons) was $100 \%(101 / 101$ patients). No patient suffered a postoperative complication while in the Department of Nuclear Medicine and there was no evidence that bringing these patients for renography immediately after surgery compromised the quality of postoperative care.

Of the 94 postoperative renographies 46 were abnormal. Forty-two showed ATN and only 4 had other findings: perigraft hematoma, infarct (eventually proven to be the result of renal vein thrombosis), mild rejection, and urine leak. Prompt surgical intervention for the patient with a perigraft hematoma led to evacuation of the hematoma and salvage of the allograft. Furthermore, prompt surgical intervention for the patient with renal vein thrombosis identified a badly infarcted allograft which could not be salvaged despite immediate surgery. Of the 42 renographies with findings typical of ATN, 23 occurred in patients receiving a cadaveric transplant and 19 in patients receiving an allograft from a living related donor.

\section{Discussion}

Although 46 postoperative renograms were abnormal, given the natural history of ATN, it could have been possible to detect 42 of these had the renogram been per- 

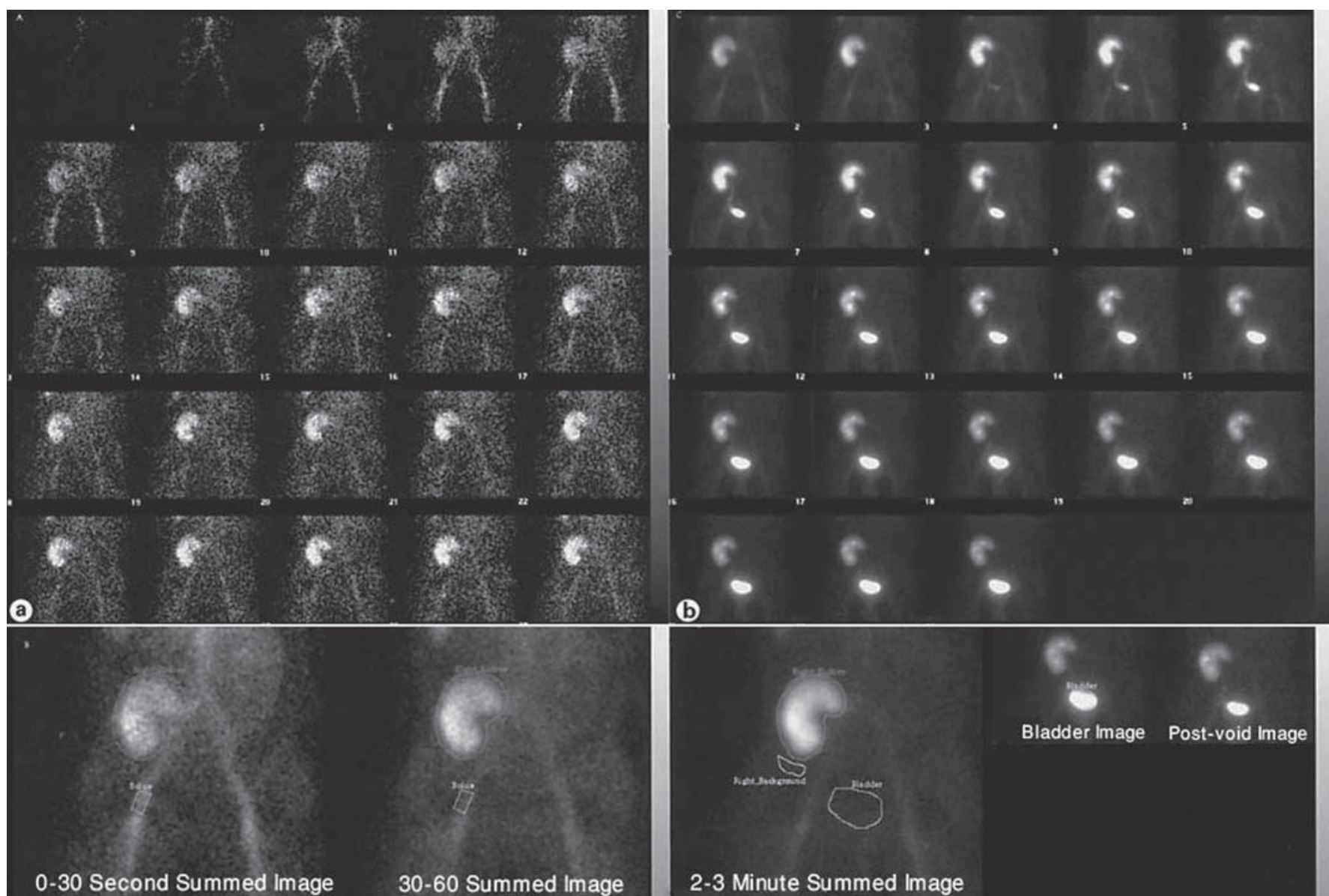

\section{0-30 Second Summed Image $\quad 30-60$ Summed Image}

2-3 Minute Summed Image
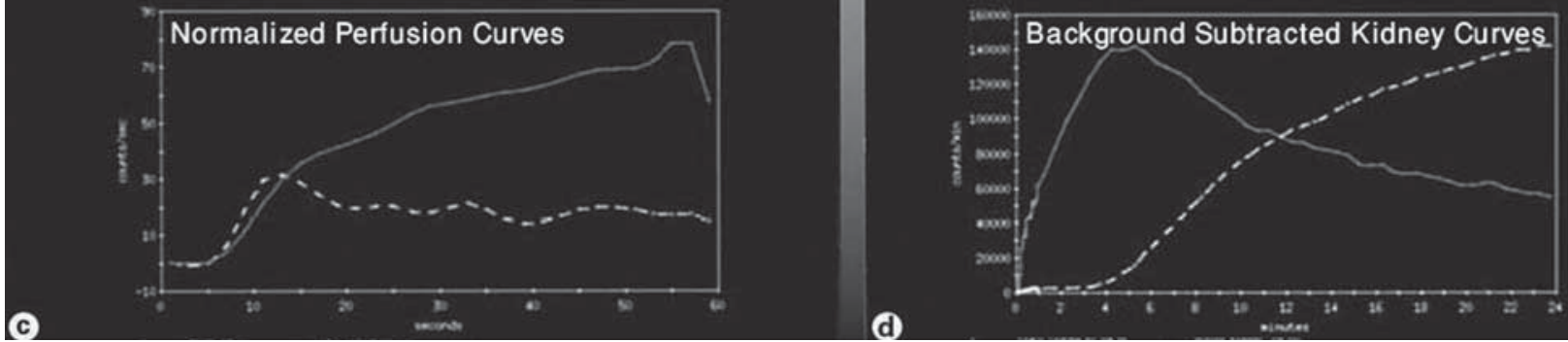

Fig. 1. A radionuclide renography study of a patient with renal transplant. The study was performed immediately following surgery. The flow study (a) obtained for 2-second frames for 1 min shows normal perfusion to the transplanted kidney. b The regions of interest used to generate the perfusion curves shown. $\mathbf{c}$ The sequential functional images obtained following the flow study. These images were obtained every $30 \mathrm{~s}$ out to 30 min and displayed as 1-min frames. The image shows good uptake, build-up and excretion of the radiopharmaceutical by the transplanted kidney, which is also shown on the time-activity curve (d).

formed between 12 and $72 \mathrm{~h}$ after surgery as previously reported [2]. Thus, the yield of possibly significant abnormalities was among 4 of 94 cases: perigraft hematoma, renal vein thrombosis, mild rejection, and urine leak. Only the cases of renal vein thrombosis and perigraft he- matoma led to prompt surgery. Only the patient with a perigraft hematoma had the allograft salvaged by immediate postoperative surgery. Treatment for the cases of mild rejection and urine leak was not surgical and probably would have been no different if the renogram had 
been obtained between 12 and $72 \mathrm{~h}$ after surgery. Thus, in this series there was only 1 patient (the case of perigraft hematoma) for whom renography within $1 \mathrm{~h}$ of renal transplantation led to prompt surgical salvage of the renal allograft. However, within the first $24 \mathrm{~h}$ following transplantation, complications resulting in sudden loss of renal transplant function are rare. In fact, in this series of 127 renal transplant recipients, these were only two complications which posed an immediate threat to the transplanted kidney within the first few hours following surgery. For both cases, the renography led to surgical intervention resulting in the salvage of one of the allografts.

Nuclear medicine, transplant surgery, anesthesiology, and nursing service worked together to provide this round-the-clock imaging service. When an allograft from a living related donor was transplanted, the postoperative renography could be scheduled 1 day in advance. Cadaveric transplants at all hours of the night and day required renographies on an emergency basis. Typically, the surgeons would call nuclear medicine personnel before be- ginning a cadaveric transplant, thus providing notice that a renogram would be required 3-4 h later. Fortunately, there were no instances in which lack of personnel, radiopharmaceutical, or an operational gamma camera prevented us from performing a transplant renogram. Anesthesiology and nursing service accompanied all patients to the Nuclear Medicine Department. Transplant surgeons always accompanied the patients as well and were prepared to intervene as needed.

\section{Conclusion}

The results indicate that renography within $1 \mathrm{~h}$ of renal transplantation was technically feasible, safe for the patient, but had minimal clinical utility. Therefore we recommend that radionuclide renography within $1 \mathrm{~h}$ posttransplant should not be performed routinely but could be done on an individual basis when imminent intervention is highly likely.

\section{References}

$>1$ Russell CD, Yang H, Gaston RS, Hudson SL, Diethelm AG, Dubovsky EV: Prediction of renal transplant survival from early postoperative radioisotope studies. J Nucl Med 2000;8: 1332-1336.

2 Dubovsky EV, Russell CD, Erbas B: Radionuclide evaluation of renal transplant. Semin Nucl Med 1995;25:49-59.

-3 Chaiwatanarat T, Laorpatanaskul S, Poshyachinda M, Boonvisut S, Buachum V, Krisanachinda A, Suvanapha R: Deconvolution analysis of renal blood flow: Evaluation of postrenal transplant complications. J Nucl Med 1994;35:1792-1796.

-4 Carmody E, Greene A, Brennan P, Donohue J, Carmody M, Keeling F: Sequential Tc-99m mercaptoacetyl-triglycine (MAG-3) renography as an evaluator of early renal transplant function. Clin Transpl 1993; 7:245-249.

5 Wellman HN, Milgrom M: Assessment of renal transplant patients with Tc-99m MAG-3: Case reports and review. Dial Transplant 1992;21:720-753.

6 6 Delbeke D, Sacks GA, Sandler MP: Diagnosis of allograft renal vein thrombosis. Clin Nucl Med 1989; 14:415-420.

7 Hilson AJW: Renal transplantation; in Maisey NM, Britton KE, Gliday EDL (eds): Clinical Nuclear Medicine. London, Chapman \& Hall, 1983, pp 124-128.
8 Brown ED, Chen MY, Wolfman NT, Ott, DJ, Watson NE Jr: Complications of renal transplantation: Evaluation with US and radionuclide imaging. Radiographics 2000;20:607622.

$\checkmark 9$ Dodd GD III, Tublin ME, Shah A, Zajko AB: Imaging of vascular complications associated with renal transplants. Am J Roentgenol 1991; 157:449-459.

10 Hohnke C, Abendroth D, Chleibner S, Land W: Vascular complications in 1200 kidney transplantations. Transplant Proc 1987; 19: 3691-3692.

11 Platt F, Ellis H, Rublin M: Renal transplant pyelocaliectasis: Role of duplex Doppler US in evaluation. Radiology 1991;179:425-428.

12 Sarkar SD, Singhal PC: Basis of renal scintigraphy; in Elgazzar A (ed): The Pathophysiologic Basis of Nuclear Medicine. New York, Springer, 2000, pp 164-167.

13 El-Maghraby TA, de Fijter JW, van Eck-Smit BL, Zwinderman AH, El-Haddad SI, Pauwels EK: Renographic indices for evaluation of changes in graft function. Eur $\mathrm{J}$ Nucl Med 1998;25:1575-1586.
14 El-Maghraby TA, van Eck-Smit BL, de Fijter JW, Pauwels EK: Quantitative scintigraphic parameters for the assessment of renal transplant patients. Eur J Radiol 1998;28:256259.

15 Dunn EK: Radioisotopic evaluation of renal transplants. Urol Radiol 1992;14:115-126.

16 Notaghi A, Merrick MV, Anderton JL, Yates PA: Value of the gamma camera renogram in the differential diagnosis of acute tubular necrosis and rejection in the early post transplant period comparison with biopsy findings. $\mathrm{Br} \mathrm{J}$ Urol 1989;63:594-599.

17 Al-Nahhas AA, Jafri RA, Britton KE, Solanki K, Bomanji J, Mather S, Carroll MA, Al-Janabi M, Frusciante V, Ajdinowic B: Clinical experience with Tc-99m MAG-3, mercapto acetyltriglycine and a comparison with Tc-99m DTPA. Eur J Nucl Med 1988;14:453-462.

$\checkmark 18$ Tisdale PL, Collier BD, Kauffman HM, Adams MB, Istiman AT, Hellman RS, Hoffman RG, Rao SA, Joestgen T, Krohn L: Early diagnosis of acute postoperative renal transplant rejection by indium-111 labeled platelet scintigraphy. J Nucl Med 1986;27:1266-1272.

19 Freeman LM, Lutzker LG: The kidneys; in Freeman LM (ed): Freeman and Johnson's Clinical Radionuclide Imaging. Orlando, Grune \& Stratton, 1984, pp 805-816. 